\title{
IMPLEMENTAÇÃO E AVALIAÇÃO DE UM PLANO DE ENSINO PARA A AUTO-IRRIGAÇÃO DE COLOSTOMIA: ESTUDO DE CASO
}

Idevânia Geraldina Costa ${ }^{1}$

Sônia Ayako Tao Maruyama²

Costa IG, Maruyama SAT. Implementação e avaliação de um plano de ensino para a auto-irrigação de colostomia: estudo de caso. Rev Latino-am Enfermagem 2004 maio-junho; 12(3):557-63.

Tendo como objetivos descrever e avaliar a implementação de um plano de ensino para a auto-irrigação da colostomia e relatar as percepções dos colostomizados relacionadas à auto-irrigação, este estudo de caso foi desenvolvido no ambulatório de colostomia do Hospital Universitário Júlio Müler, do município de Cuiabá, no período de fevereiro a março de 1997. O plano de ensino proposto favoreceu a esses colostomizados a aprendizagem quanto à técnica de irrigação e a reinserção social.

DESCRITORES: colostomia; irrigação; reabilitação

\section{IMPLEMENTATION AND EVALUATION OF A TEACHING PLAN FOR THE AUTO-IRRIGATION OF COLOSTOMY: A CASE STUDY}

With a view to describing and evaluating the implementation of a teaching plan for the auto-irrigation of colostomy and reporting on the perceptions of colostomized patients related to auto-irrigation, this case study was developed at the colostomy out-patient clinic of the Júlio Müller University Hospital, Cuiabá, Brazil, from February to March 1997. The teaching plan helped the patients to learn about the irrigation technique and social rehabilitation.

DESCRIPTORS: colostomy; irrigation; rehabilitation

\section{PLANO DE ENSEÑANZA PARA LA AUTO-IRRIGACIÓN DE LA COLOSTOMÍA: ESTUDIO DE CASO}

Con la finalidad de describir y evaluar la implementación de un plano de enseñanza para preparar al colostomizado para la auto-irrigación y relatar las percepciones de pacientes colostomizados sobre auto-irrigación, este estudio de caso fue desarrollado en el ambulatorio de colostomía del Hospital Universitario Julio Müler del municipio de Cuiaba, en el periodo de febrero a marzo de 1997. El plano de enseñanza propuesto ayudó a estos colostomizados en el aprendizaje de la técnica de irrigación y la reinserción social.

DESCRIPTORES: colostomía; irrigación; rehabilitación

\footnotetext{
${ }^{1}$ Enfermeira, Docente da Faculdade de Enfermagem da Universidade de Cuiabá, Mestranda do Programa de Enfermagem Fundamental, e-mail: idevania@terra.com.br; ${ }^{2}$ Docente da Faculdade de Enfermagem da Universidade Federal de Mato Grosso, Doutoranda do Programa de Enfermagem Fundamental. Escola de Enfermagem de Ribeirão Preto, da Universidade de São Paulo, Centro Colaborador da OMS para o desenvolvimento da pesquisa em enfermagem
} 
INTRODUÇÃO

$\boldsymbol{O}$ impacto de uma colostomia na vida de qualquer pessoa traz conseqüências que se refletem nos diferentes aspectos, entre eles, o biológico, o psicológico, o social e o espiritual, sendo a alteração da auto-estima uma das mais importantes.

O colostomizado é uma pessoa que necessitou realizar uma abertura na parede abdominal, denominada de estoma, para desviar a eliminação intestinal, podendo ser temporária ou permanente. A colostomia temporária pode ser decorrente de um trauma ocasionado por arma branca ou arma de fogo na região colônica, e a colostomia permanente, normalmente acontece nos casos de neoplasia no cólon ou reto cuja conseqüência é a amputação do trato intestinal comprometido. A característica desses pacientes é a perda da continência intestinal, resultando em saída constante das eliminações intestinais pelo estoma, e isso leva ao uso constante de uma bolsa de colostomia. Entretanto, nem sempre esses clientes possuem uma bolsa adequada para evitar os incômodos resultantes dessa alteração, fato este que compromete suas relações sociais. Assim, para minimizar o impacto social advindo por esses incômodos, a atenção dispensada pelos profissionais que participam na assistência aos colostomizados, é relevante no sentido de proporcionar uma reabilitação que vise adaptá-lo à sua nova condição de vida.

Uma assistência de enfermagem adequada, visando à reabilitação do colostomizado, minimiza as conseqüências biopsicossociais decorrentes de uma colostomia. O enfermeiro estomaterapeuta é o profissional apto a assistir esses pacientes e o objetivo de sua atenção deve ser promover a sua independência e a sua autoestima, para uma vida mais digna.

O processo de reabilitação desenvolvido pelo profissional deve visar à continuidade do tratamento; desenvolver a capacidade de aprendizado para o autocuidado; contribuir para o retorno da pessoa às suas atividades; incentivar a ajustar-se ao novo estilo de vida $e$ assegurar o empenho da família e da comunidade no processo de reabilitação ${ }^{(1)}$.

Reabilitar significa preparar os colostomizados para lidar com todos os medos, fantasias e ansiedades, reintegrando-os às condições de vida; isso pode ser alcançado pela implementação de programas educacionais $^{(2)}$.

Dentre um dos aspectos educacionais para os colostomizados, salientamos o ensino da técnica da auto- irrigação intestinal, pois ela possibilita à pessoa controlar as eliminações intestinais e, com isso, sua reinserção nas atividades sociais. A auto-irrigação da colostomia reduz os problemas relacionados à incontinência fecal, às alterações da pele periestomal, à troca constante das bolsas coletoras, ao controle do odor e aos ruídos desagradáveis, isto é, à sensação do "inesperado", minimizando, dessa forma, os traumas psicossociais.

A auto-irrigação age da mesma forma que o enema, distendendo o intestino e estimulando a peristalse e, com isso, o esvaziamento do conteúdo fecal, gazes e odor. É importante utilizar a técnica e os dispositivos adequados, pois isso evita o risco de perfuração intestinal ${ }^{(3)}$. Os dispositivos, atualmente utilizados na técnica da auto-irrigação, reduzem significativamente os riscos de complicações decorrentes da perfuração de alça intestinal.

As finalidades do método de auto-irrigação são: estimular o peristaltismo em massa; promover a eliminação intestinal e regular a evacuação; diminuir a flora bacteriana, os gases e o odor, e reduzir o uso de dispositivos coletores e o aparecimento de lesões periestomal, contribuindo para a melhora da qualidade de vida do colostomizado ${ }^{(4)}$.

A técnica de auto-irrigação é indicada aos portadores de colostomias esquerdas (de cólon descendente ou sigmóide), terminais e definitivas. Porém, fatores como a idade, a doença de base, outras patologias associadas, as alterações do estoma, as condições sociais e culturais também devem ser avaliados para 0 ensino da técnica ${ }^{(4)}$.

Os benefícios dessa técnica têm sido superiores ao uso dos métodos naturais de controle da incontinência intestinal. Os fatores como a melhoria dos dispositivos para auto-irrigação e os estudos que comprovam sua eficácia, estão estimulando os colostomizados e profissionais a optarem por essa técnica.

Mesmo sabendo de seus benefícios, é importante uma criteriosa avaliação do paciente, das suas condições biológicas, psicológicas e socioculturais, esclarecendo todas as dúvidas que surgem, deixando que o colostomizado decida sobre a realização ou não da técnica.

As vantagens da auto-irrigação devem ser relatadas pelos próprios pacientes. Estudos comprovam a melhora no ajustamento emocional e social, devido à segurança e redução da ansiedade dos colostomizados ${ }^{(4)}$.

$O$ consumo de tempo, de 45 a 60 minutos $^{(3)}$, e a limitação da aplicação aos colostomizados, além dos índices residuais de resultados ineficientes, são destacados por alguns autores como desvantagens da 
técnica ${ }^{(4)}$.

Apesar dos fatores mencionados, a técnica da auto-irrigação ainda se constitui em uma estratégia de controle intestinal que favorece a reinserção social do indivíduo e uma alternativa eficaz para sua reabilitação, devido a seu baixo custo.

Consciente desses aspectos, o enfermeiro deve assistir esses pacientes de forma sistemática, atento aos cuidados a serem tomados antes, durante e após a realização da auto-irrigação da colostomia, bem como informando-os dos fatores relacionados à técnica e, nesse sentido, salientamos a importância da educação em saúde, na reabilitação dos colostomizados.

É importante a elaboração de um plano de ensino para a auto-irrigação intestinal do colostomizado, como parte da sistematização da assistência de enfermagem.

Assim, o objetivo deste estudo é descrever e avaliar a implementação de um plano de ensino para a auto-irrigação da colostomia e relatar as percepções dos colostomizados antes, durante e após o ensino da técnica de irrigação intestinal.

\section{METODOLOGIA}

Trata-se de uma pesquisa do estudo do tipo, realizado no Ambulatório de Ostomias do Hospital Universitário Júlio Müller, do município de Cuiabá/MT.

O estudo de caso é um tipo relevante de pesquisa qualitativa em que o objeto é uma unidade que se analisa com detalhes e em profundidade. O caso, sendo uma unidade significativa do todo, é considerado suficiente para fundamentar um julgamento fidedigno e propor uma intervenção. Além disso, também constitui um marco de referência de complexas condições socioculturais que envolvem uma situação e, por isso, retrata não só a realidade como revela a multiplicidade de aspectos globais presentes em uma dada situação ${ }^{(5)}$. Tal característica permite a descrição, a exploração e a compreensão do comportamento humano de aspectos determinados da vida de uma pessoa, pelas narrativas na primeira pessoa coletadas por meio de entrevistas semi-estruturadas ${ }^{(6)}$. Assim, esse tipo de estudo foi considerado o adequado para descrever a percepção dos colostomizados em relação à auto-irrigação.

Os critérios para inserção dos sujeitos neste estudo, além das indicações referenciadas anteriormente, foram: ser paciente do ambulatório, estar consciente; estar motivado à realização da técnica de auto-irrigação; ter idade superior a 18 anos e aceitar a participar do estudo, no período de fevereiro a março de 1997. Assim, dois pacientes atenderam esses critérios, sendo: uma do sexo feminino, 57 anos, costureira e residente em Cuiabá, e o outro, do sexo masculino, 68 anos, aposentado vindo do Acre, porém com residência provisória em Cuiabá.

O plano de ensino para irrigação da colostomia, seguiu a proposta de experiências anteriores de outros autores $^{(7)}$, e o desenvolvimento do cliente durante o plano de ensino foi registrado no formulário específico de consulta de enfermagem do ambulatório. Esse registro constitui os dados relacionados ao ensino da auto-irrigação.

As percepções dos colostomizados foram dados importantes coletados após o ensino da técnica, pois a literatura afirma que cabe somente aos clientes avaliarem e descreverem as vantagens da auto-irrigação de sua colostomia.

O ensino da técnica de irrigação teve por base a aplicação de um plano de ensino (Figura 1), descrito em outro estudo $^{(4)}$, o qual foi adaptado para a realidade de nosso serviço.

\begin{tabular}{|c|c|c|c|c|c|c|}
\hline D ia & F ase & O b jetivo & $\begin{array}{c}\text { Estratégia/ } \\
\text { Tem po }\end{array}$ & Recursos & A va lia ção & Observações \\
\hline \multirow[t]{2}{*}{$1^{\circ} \mathrm{dia}$} & $\begin{array}{c}\text { A valiação } \\
\text { D iagnóstica }\end{array}$ & $\begin{array}{l}\text { Levantara } \\
\text { informação } \\
\text { acerca da } \\
\text { irrigação } \\
\text { intestinal. }\end{array}$ & $\begin{array}{c}\text { Entrevistase } \\
\text { explicação } \\
\left(30^{\prime}\right)\end{array}$ & $\begin{array}{c}\text { Formulário } \\
\text { Específico } \\
\text { de consulta de } \\
\text { enferm agem, cartazes } \\
\text { explicativo. }\end{array}$ & $\begin{array}{l}\text { Verificar informações } \\
\text { sobre a técnica; }\end{array}$ & \\
\hline & M o tiv a çã o & $\begin{array}{c}\text { Descrever, passo } \\
\text { a passo, a técnica } \\
\text { de irrigação } \\
\text { intestinalao } \\
\text { Colostomizado. }\end{array}$ & $\begin{array}{c}\text { A presentação oral } \\
\left(30^{\prime}\right)\end{array}$ & Cartazes & $\begin{array}{c}\text { Identificar } \\
\text { interesse durante a } \\
\text { explicação da técnica }\end{array}$ & \\
\hline $2 \circ \mathrm{dia}$ & $\begin{array}{l}\text { Ensinar a } \\
\text { técnica de } \\
\text { irrigação }\end{array}$ & $\begin{array}{c}\text { Demonstrare } \\
\text { realizara técnica } \\
\text { de irrigação da } \\
\text { colostom ia para o } \\
\text { cliente }\end{array}$ & $\begin{array}{l}\text { Prática } \\
(1 \text { hora })\end{array}$ & $\begin{array}{c}\text { Irrigador completo, cinto } \\
\text { elástico, presilhas, } \\
\text { glicerina líquida, suporte } \\
\text { para irrigador, água } \\
\text { morna tratada, luvas, } \\
\text { placase bolsas e } \\
\text { relógio. }\end{array}$ & $\begin{array}{c}\text { Verificara aceitação e } \\
\text { o grau de } \\
\text { entendimento das } \\
\text { explicações (porm eio } \\
\text { de perguntas) }\end{array}$ & \\
\hline 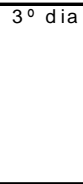 & $\begin{array}{l}\text { Devolução da } \\
\text { Técnica pelo } \\
\text { colostom i-zado }\end{array}$ & $\begin{array}{c}\text { Detectaras } \\
\text { possíveis } \\
\text { complicações } \\
\text { e/ou dificuldades } \\
\text { durante e após a } \\
\text { realização da } \\
\text { técnica (pelo } \\
\text { cliente). }\end{array}$ & $\begin{array}{c}\text { Observare registrar } \\
\text { (1 hora) }\end{array}$ & $\begin{array}{l}\text { Formulário específico da } \\
\text { consulta de enfermagem }\end{array}$ & $\begin{array}{c}\text { Verificação de } \\
\text { habilidades para au to- } \\
\text { irrigar-se, sem auxilio }\end{array}$ & \\
\hline
\end{tabular}

Fonte: adaptado de Santos VLCG, Cezareti IUR, Ribeiro AM, Filippin MJ, Lima SRS

Figura 1 - Plano de ensino, elaborado para preparar o colostomizado para a auto-irrigação 
Quanto à estratégia para o ensino da técnica, seguiram-se as orientações de algumas autoras ${ }^{(8)}$ que já realizaram vários estudos sobre o ensino da técnica de irrigação aos colostomizados. Dessa forma, o treinamento foi realizado em três fases, sempre no mesmo horário e em dias consecutivos, conforme o plano de ensino apresentado. Na última fase do treinamento, procuramos certificar se os pacientes estavam aptos para a autoirrigação, considerando-se os critérios ${ }^{(8)}$ listados a seguir: - descreve os passos da técnica de irrigação;

- identifica a altura adequada da base do irrigador, tomando como base seu próprio ombro, estando sentada ou em pé;

- reconhece que a água morna é a temperatura adequada; - introduz o cone no estoma, após a retirada do ar do sistema;

- introduz e mantém o cone na colostomia, de forma adequada, sem comprimi-la e sem deixar vazar água;

- infunde a água em velocidade contínua, em um tempo de 5 a 10 minutos;

- impede a entrada de ar no intestino, ao encerrar a fase de infusão;

- reconhece e consegue solucionar os principais problemas que podem ocorrer durante e após a irrigação;

- descreve os cuidados de conservação e limpeza do equipamento para a irrigação.

Em relação ao plano de ensino, fez-se uma descrição da aplicação deste para os dois clientes.

Os relatos foram coletados após o ensino da referida técnica, por meio da entrevista semi-estruturada, sendo que as questões norteadoras foram:

- Como era sua "vida" antes do ensino da técnica da autoirrigação intestinal (convívio social, familiar...)?

- Como sentiu ao ser demonstrada a técnica da autoirrigação da colostomia pela enfermeira?

- Como passou a ser sua vida após ter aprendido a técnica da auto-irrigação da colostomia?

Uma vez coletados, os relatos foram apresentados e discutidos com base na revisão da literatura.

Em cumprimento aos aspectos éticos, por ainda não ter sido implantado o Comitê de Ética em Pesquisa no Hospital, na época em que ocorreu o estudo, seguimos os critérios éticos de pesquisa em seres humanos, respeitando a concordância das participantes.

Com o intuito de manter o anonimato dos entrevistados, eles foram identificados com as letras do alfabeto.

\section{RESULTADOS E DISCUSSÕES}

O ensino da técnica da irrigação da colostomia

No primeiro dia, os pacientes A e B mostraramse interessados e motivados para a realização da técnica, escutando e observando, atentamente, as informações e as explicações. Ainda fizeram perguntas relativas ao fornecimento do material, a água a ser utilizada e o tempo para realizar a técnica.

No segundo dia, foi realizada a técnica da autoirrigação com os clientes, sendo que tanto o paciente $A$ como o B demonstraram estar estimulados para fazer o procedimento, questionando a quantidade e a temperatura da água, a altura adequada do irrigador e o tempo de infusão e da drenagem, além de realizarem as massagens abdominais e a deambulação para auxiliar na drenagem do efluente.

No terceiro dia, durante a devolução da técnica, não houve complicações ou intercorrências, os clientes sentiram-se seguros, seguiram os passos corretamente, mostrando-se competentes para a auto-irrigação.

Um dos fatores imprescindíveis ao aprendizado de qualquer conhecimento é a disposição do indivíduo, a motivação para o aprendizado e, para isso, é necessário que o mesmo decida a real necessidade de aprender sobre determinado aspecto ${ }^{(9)}$.

A satisfação das necessidades de aprendizagem do paciente é uma parte essencial da função do enfermeiro. A enfermeira deve ter conhecimento sobre o processo de aprendizagem; ser capaz de identificar as dificuldades de aprendizagem e selecionar os métodos e as técnicas apropriadas que facilitem esse processo. A maneira mais apropriada para facilitar o aprendizado, inclui a demonstração do procedimento, a explicação das razões para as suas várias etapas, a repetição da demonstração e a realização da técnica pelo paciente. A enfermeira pode avaliar a eficácia da aprendizagem interrogando o paciente e observando a forma como ele desenvolve a técnica ${ }^{(10)}$.

A orientação da realização diária, no mesmo horário, por um período de seis meses, deve ser reavaliada após esse tempo, pois esta freqüência pode ser alterada para 48 a 72 horas. Um outro aspecto a ser esclarecido é a não realização da auto-irrigação em jejum absoluto e após as refeições, informando-os de que o ideal é iniciar o procedimento após um intervalo de, pelo menos, duas horas após as refeições ${ }^{(4)}$. 
Quanto aos recursos materiais disponíveis para o ensino da técnica, os colostomizados tiveram acesso ao sistema completo de irrigação, as bolsas de colostomias e a um folheto de orientações para realização do procedimento.

Explicar a técnica, demonstrar e praticar são estratégias essenciais do programa de ensino para os pacientes. É relevante que a enfermeira demonstre a técnica e posteriormente ofereça ao cliente a oportunidade para praticá-la. Além disso, destaca-se a importância do acesso ao material adequado para o paciente ${ }^{(10)}$.

A percepção dos colostomizados após o ensino da técnica da auto-irrigação

Estão apresentadas de acordo com o roteiro da entrevista:

Percepção do colostomizado antes do ensino da técnica da auto-irrigação da colostomia

Os dois entrevistados apresentavam problemas de reinserção social antes da realização da auto-irrigação, visto que o funcionamento intestinal é imprevisível, e o colostomizado não tem mais o controle de seus hábitos intestinais. Esses problemas são expressos por eles, pelo afastamento de suas atividades diárias, isolamento social e desesperança.

...eu não sentia bem ficando assim, devido ao mau cheiro. Então eu ficava assim, com vergonha... Queria ficar isolada das pessoas, tinha vergonha de ir pra igreja, ficava com vergonha de ficar perto das pessoas... Parecia que o povo que chegava perto de mim estava sentindo... (emocionada) (A).

...às vezes ficava tudo sujo, né. Eu sentia até desgosto daquilo, estava descrente e sem fé. Tinha medo de aproximar das pessoas. A minha família falava: mas como é que existe isso? Sai cocô pela barriga! (B).

Dessa forma, podemos constatar os problemas sociais e os emocionais como os mais freqüentes apresentados pelos colostomizados ${ }^{(2)}$.

As alterações sociais relatadas pelos colostomizados entrevistados estão relacionadas ao:

- isolamento familiar e social;

- perda do controle das eliminações e de ruídos, levando à dependência do sanitário;

- eliminação de odores desagradáveis e eliminação de fezes, levando à marginalização social; - perda da capacidade de conviver nos grupos sociais; Quanto às alterações espirituais, foram relatadas:
- descrença e desânimo (somente para B);

- necessidade de apoio emocional (tanto para o A como para o B).

Nos relatos, percebe-se a repercussão social e emocional da colostomia na vida desses indivíduos, sendo um dos mais importantes o isolamento social. Por isso, destacamos a necessidade de apoio em todos os aspectos do ser humano. Nesse sentido, enfatizamos a relevância de uma assistência de enfermagem qualificada, no processo de reabilitação do colostomizado, para que possa ter uma vida com qualidade.

Percepção do colostomizado durante o ensino da técnica da auto-irrigação da colostomia

Observou-se que a demonstração da técnica da auto-irrigação da colostomia, passo a passo, ao colostomizado contribuiu para: atingir os objetivos propostos no plano de ensino e motivar a sua aplicação.

Um dos aspectos fundamentais ao ensino da técnica é avaliar o conhecimento prévio sobre ela, antes de se realizar o ensino e, nesse sentido, um dos pacientes relatou:

... eu já tinha ficado sabendo disso, falavam para minha irmã que tinha um jeito de educar o intestino, aí eu pensei, será como é? Quando eu fui lá no ambulatório foi que a enfermeira me explicou, né. Eu achei muito legal! Fiquei muito contente! (A).

O colostomizado que tem uma informação anterior à auto-irrigação da colostomia, dada por profissional de saúde ou por outros colostomizados, muitas vezes, demonstra um interesse maior para a aprendizagem. Porém, mesmo sem um conhecimento prévio por parte do paciente, o colostomizado, ao se informar da autoirrigação da colostomia, vê uma possibilidade de minimizar seus problemas e facilitar o retorno da pessoa às suas atividades anteriores:

..Achei legal! não sabia que existia essa técnica. Sabia só da lavagem, mas só aqui atrás (apontando para o ânus). Quando a enfermeira me ensinou, fiquei feliz e logo aprendi a maneira de fazer (B).

A educação para a irrigação intestinal da colostomia ainda é pouco divulgada em nossa sociedade, o que pode estar relacionado à falta de conhecimento por parte dos profissionais de saúde ou à deficiência de recursos materiais. Nesse aspecto, salientamos o papel da enfermeira como educadora do paciente colostomizado em fase de reabilitação, principalmente quanto o método de irrigação intestinal. Salienta-se a relevância do 
enfermeiro estomaterapeuta ou não, mas com treinamento para o ensino da técnica ${ }^{(7)}$. É importante o enfermeiro estar atento para a especificidade de cada alteração de saúde e às mudanças no tratamento das doenças e estar aberto à aquisição de novos conhecimentos que possibilitem uma assistência profissional qualificada, com vistas a uma adequada reabilitação desse grupo de pacientes.

Percepção do colostomizado após o ensino e a realização da técnica da auto-irrigação da colostomia

Foi interessante observar que as vantagens da técnica da auto-irrigação da colostomia, descritas pela literatura, foram percebidas pelos colostomizados do estudo, relatadas por sentimentos de felicidade e satisfação.

Após o ensino e aplicação da técnica, percebeuse a possibilidade de reinserção social, quando os pacientes começam a fazer planos sobre o futuro, retornam a participar de festas, ir à igreja e a fazer tudo que não faziam antes da aprendizagem e realização da técnica de irrigação. Isso nos permite dizer que a implementação da técnica da auto-irrigação proporciona aos colostomizados uma melhora da qualidade de vida.

A irrigação é boa porque eu fico tranqüila, não fico com preocupação de evacuar toda hora, a gente não tem aquela vontade... Com a irrigação sai tudo, fico até um dia sem evacuar. Agora, se eu vou para festa é só fazer a irrigação, não tem perigo da bolsinha ficar cheia. Para dormir também, é melhor, que a bolsinha não enche, e eu durmo tranqüila. Fiquei muito contente! ( $A$ ).

O bem-estar do colostomizado é um dos maiores objetivos da sua reabilitação, estimulando o indivíduo a desenvolver ao máximo suas potencialidades, reintegrando0 , gradativamente, às atividades diárias ${ }^{(12)}$.

O controle sobre a eliminação intestinal pela técnica da auto-irrigação está relacionado à redução da ansiedade, como demonstra o relato abaixo:

Mais legal, porque, antes, o cocô dava (pausa) não saia direito, tava duro. Agora tá um cocô mais grande, porque a lavagem descarrega tudo, né. Eu fico mais tranqüilo, né, durmo mais tranqüilo. Depois da lavagem, melhorou $100 \%$, fico mais tempo sem fazer $\operatorname{cocô!}(B)$.

A irrigação da colostomia, permite o esvaziamento total do intestino, mesmo em casos de constipação, porém é necessário que o paciente seja orientado quanto aos padrões nutricionais, a fim de adequar seus hábitos alimentares. Nesse caso, o enfermeiro pode informá-lo ou solicitar o acompanhamento de um profissional especializado, visto que, no cuidado com os colostomizados, é importante a assistência por uma equipe multiprofissional.

\section{CONSIDERAÇÕES FINAIS}

O plano de ensino proposto para a auto-irrigação intestinal possibilitou a aprendizagem dos colostomizados para realizarem a técnica, permitindo a redução dos problemas físicos, sociais e emocionais dos entrevistados.

Constatou-se a melhora da qualidade de vida para esses colostomizados, uma vez que a irrigação da colostomia possibilitou a minimização das alterações sociais e emocionais percebidas por eles, por sentimentos positivos.

A auto-irrigação facilita a convivência do colostomizado no seu meio social e promove a sua saúde, pois minimiza as alterações psicológicas, sociais e biológicas. Vimos, também, que as desvantagens da técnica não são maiores do que os incômodos e as conseqüências de uma colostomia na vida de uma pessoa. Apesar disso, sugerimos que novas pesquisas sejam realizadas para aumentar os resultados positivos e minimizar as desvantagens da técnica.

Um dos aspectos relevantes quanto ao ensino da técnica é a participação dos familiares, principalmente quando o paciente não se sente totalmente seguro para realizá-la, sem acompanhamento, ou quando os colostomizados têm alguma deficiência. $O$ apoio da família serve de incentivo para a redução da insegurança e da ansiedade.

No processo de reabilitação, o ensino do paciente é um aspecto essencial da assistência de enfermagem a ele. Deve-se ensinar as pessoas a viver de modo mais saudável, ou seja, tentar atingir o potencial máximo de saúde do indivíduo. O ensino a essas pessoas está relacionado com o proporcionar informações em relação aos cuidados nos aspectos físico, psicológico e social, não só durante a internação, como também após a alta hospitalar. O indivíduo precisa aprender uma nova forma de viver e lidar com a sua condição de colostomizado ${ }^{(9)}$. 


\section{REFERÊNCIAS BIBLIOGRÁFICAS}

1. Nogueira AS, Santos ER, Boccardo LM, Santos VLCG, Miyadahira AMK. Auto-cuidado do ostomizado: dificuldades percebidos após a alta hospitalar. Rev Esc Enfermagem USP 1994 dez; 28(3):309-19.

2. Zerbeto GM. Reabilitação do paciente ostomizado. Rev Paul Enfermagem 1981 jan/fev; 0(0):16-20.

3. Potter PA, Perry AG. Fundamentos de enfermagem: conceitos, processo e prática. $4^{a}$ ed. Rio de Janeiro (RJ): Guanabara Koogan; 1997.

4. Santos VLCG, Cezareti IUR, Ribeiro AM, Filippin MJ, Lima SRS. Métodos de controle do hábito intestinal em estomizados: auto-irrigação e sistema oclusor. In: Crema E, Silva R. Estomas uma abordagem interdisciplinar. Uberaba (MG): Pinti; 1997.

5. Chizzotti A. Pesquisa em ciências humanas e sociais. $4^{\text {a }}$ ed. São Paulo (SP): Cortez; 2000.

6. Bogdan R, Biklen S. Investigação qualitativa em educação: uma introdução a teoria e aos métodos. Portugal: Porto Editora; 1991.

7. Santos VLCG. Relato de experiência no treinamento da irrigação intestinal em uma paciente colostomizada. Rev Paul Enfermagem 1985 abr/jun; 2(2):73-6.

8. Santos VLCG, Koizumi MS. Estudo sobre os resultados da irrigação em colostomizados submetidos a um processo de treinamento sistematizado. Rev Esc Enfermagem USP 1992 dez; 26(3):303-14.

9. Atkinson, Murray. Processo de Enfermagem. Rio de Janeiro (RJ): Guanabara Koogan; 1989.

10. Du Gas BW. Enfermagem Prática. Rio de Janeiro (RJ): Interamericana; 1978.

11. Smeltzer SC, Bare BG. Tratado de Enfermagem MédicoCirurgico. Rio de Janeiro (RJ): Guanabara Koogan; 1994.

12. Santos VLCG, Koizumi MS. Sentimentos e sugestões manifestados por colostomizados que se auto-irrigam. Rev Esc Enfermagem USP 1992 agosto; 26(2):161-71. 